\title{
Collagen COL4A3 knockout: a mouse model for autosomal Alport syndrome
}

\author{
Dominic Cosgrove, ${ }^{1,3}$ Daniel T. Meehan, ${ }^{1}$ James A. Grunkemeyer, ${ }^{1}$ Jody M. Kornak, ${ }^{1}$ \\ Robinlyn Sayers, ${ }^{1}$ William J. Hunter, ${ }^{2}$ and Gina C. Samuelson ${ }^{1}$ \\ ${ }^{1}$ Department of Genetics, Boys Town National Research Hospital, Omaha, Nebraska 68131 USA; ${ }^{2}$ Department of Pathology, \\ Creighton University School of Medicine, Omaha, Nebraska 68178 USA
}

\begin{abstract}
A mouse model for the autosomal form of Alport syndrome was produced. These mice develop a progressive glomerulonephritis with microhematuria and proteinuria, consistent with the human disease. End-stage renal disease develops at $\sim 14$ weeks of age. TEM analysis of the glomerular basement membranes (GBM) during development of renal pathology revealed focal multilaminated thickening and thinning beginning in the external capillary loops at 4 weeks and spreading throughout the GBM by 8 weeks. By 14 weeks, half of the glomeruli were fibrotic with collapsed capillaries. Immunofluorescence analysis of the GBM showed the absence of type IV collagen $\alpha-3, \alpha-4$, and $\alpha-5$ chains and a persistence of $\alpha-1$ and $\alpha-2$ chains (these chains normally localize to the mesangial matrix). Northern blot analysis using probes specific for the collagen chains illustrate the absence of COL4A3 in the knockout, whereas mRNAs for the remaining chains are unchanged. An accumulation of fibronectin, heparan sulfate proteoglycan, laminin-1, and entactin was observed in the GBM of the affected animals. The temporal and spatial pattern of accumulation was consistent with that for thickening of the GBM as observed by TEM. Thus, expression of these basement membrane-associated proteins may be involved in the progression of Alport renal disease pathogenesis. The levels of mRNAs encoding the basement membrane-associated proteins at 7 weeks were unchanged.
\end{abstract}

[Key Words: Basement membrane; mouse model; Alport syndrome]

Received August 1, 1996; revised version accepted October 23, 1996.

Alport glomerulonephritis is a progressive disease of the glomerular basement membranes (GBM) resulting from mutations in the basement membrane (type IV) collagen genes. The X-linked form of the disease is the most prevalent, accounting for $>90 \%$ of reported cases and is caused by mutations in the COL4A5 gene (Barker et al. 1990|. The autosomal form of the disease is caused by mutations in either the COL4A3 or COL4A4 genes (Lemmink et al. 1994; Mochizuki et al. 1994). The frequency of the disease in humans is estimated at 1 in 20,000 (Atkin et al. 1988; Wester et al. 1995). Diffuse leiomyomatosis presents with neuromuscular degeneration in addition to the symptoms normally manifest in Alport patients and is caused by mutations that oblate both COL4A5 and COL4A6 genes (Zhou et al. 1993). In addition to glomerulonephritis, about half of Alport patients present with anterior lenticonis (Thompson et al. 1987) and a progressive, high-frequency, moderate sensorineural hearing loss (Myers and Tyler 1972; Johnsson and Arenberg 1981).

Type IV collagen is found almost exclusively in basement membranes. Of the six chains, COL4Al and

\footnotetext{
${ }^{3}$ Corresponding author.
}

COL4A2 are found in nearly all basement membranes, whereas the remaining chains have a more limited distribution (Ninomiya et al. 1995). The genes encoding these chains are arranged in a head-to-head configuration and transcribed in opposite directions, with COL4Al paired with COL4A2, COL4A3 paired with COL4A4, and COL4A5 paired with COL4A6 (Hudson et al. 1993). When translated, the resulting $\alpha$-chains associate with one another to form a triple helical protomer in which an internal Gly-X-Y $\boldsymbol{\alpha}$-helix is flanked by globular domains on both the amino (7S domain) and carboxyl ( $\mathrm{NCl}$ domain) termini (Hudson et al. 1993; Sugimoto et al. 1994). Although it is known that two COL4Al chains will associate with one COL4A2 chain to form the most common protomer (Timpl et al. 1981), the rules governing protomer formation from the remaining chains are still unclear. Absence of all three chains (COL4A3, COL4A4, and COL4A5) from the GBM of patients with either the X-linked (Kashtan and Kim 1992; Antignac et al. 1994) or autosomal form (Gubler et al. 1995) of Alport syndrome suggests an obligatory association between these chains (at least in the GBM). Four 7S domains associate with one another through noncovalent interactions, and two NC1 domains associate via covalent (disulfide bonds) and noncovalent interactions to form a chicken wire-like 
suprastructure. Covalent dimerization at the $\mathrm{NCl}$ domain occurs primarily between like $\alpha$-chains /Gunwar et al. 1991); however, significant amounts of heterodimers between COL4A3 and COL4A5 chains have been reported (Kleppel et al. 1992). It has been suggested that the COL4A1 and COL4A2 chains form a network of GBM that is separate from that formed by the remaining chains (Kleppel et al. 1992); however, reports of heterodimers between COL4A5 an COL4A1 (Derry et al. 1994) and COL4A3 and COL4A1 (Saus et al. 1988) put this theory in question.

The biodiversity of basement membranes relies in part on the collagen chain composition (tissue-specific influences on basement membrane assembly might also play a role) and in part on the multitude of proteins that associate with basement membranes. The major basement membrane-associated proteins include fibronectin, the laminins, heparan sulfate proteoglycan (HSPG), and entactin (also called nidogen). In addition to these common constituents, a variety of other biomolecules are associated with basement membranes, often to a lesser degree. The composition, distribution, and density of these basement membrane-associated proteins surely have a profound influence on normal basement membrane properties, as well as the loss of these properties during a progressive disease pathogenesis.

Renal biopsies from patients with Alport glomerulonephritis have been examined for changes in glomerular extracellular matrix. Basement membrane collagen chains COL4A1 and COL4A2 and collagens $V$ and VI are normally expressed in the mesangial matrix and to a much lesser degree in the subendothelial region of the GBM (Desjardins et al. 1990). In obsolescent glomeruli of patients with Alport syndrome, these molecules are present throughout the entire width of the GBM (Kash$\tan$ and Kim 1992). Mutations in the COL4A3, COL4A4, or COL4A5 genes result in the absence of all three chains in GBM (Kashtan and Kim 1992; Gubler et al. 1995)

In an attempt to better understand the molecular nature of Alport basement membrane pathology, we have used gene targeting technology to produce a murine model for the autosomal form of the disease /a collagen COL4A3 knockout). Herein, we describe that the clinical and ultrastuctural changes associated with the disease progression are very similar to that reported in studies of humans with the disease. Immunofluorescence analysis for expression of the basement membrane-associated proteins suggests that accumulation of fibronectin, entactin, laminin-1, and HSPG may play a key role in disease pathogenesis. These observations could, however, be secondary to the root cause of Alport glomerulonephritis. Nevertheless, this is a novel observation attesting to the utility of the model in deciphering the molecular nature of disease onset and progression. The model should provide an ideal testing ground for potential therapies. Because of the scope of the studies needed to adequately describe the initial characterization of this human disease model, this paper focuses on the renal manifestations.

\section{Results \\ Production of COLAA3 knockout}

An $8.5-\mathrm{kb}$ Pst I fragment containing the exons encoding the NCl domain of collagen COL4A3 (at the carboxyl terminus/and the $3^{\prime}$-untranslated sequence was cloned from a murine genomic library and sequenced. The 4.3$\mathrm{kb}$ Pst I fragment indicated in Figure 1A was subcloned, and the neomycin phosphotransferase (PMCINeoPA; Stratagene) cassette was cloned into exon 5 (the exons are numbered from the carboxyl terminus, because the 5' end of this gene has not been cloned) in reverse orientation so as to completely disrupt the $\mathrm{NCl}$ domain, which is a highly conserved functional domain of the collagen chain. The resulting construct was subcloned into a vector containing the diptheria toxin A-fragment (DTA) expression cassette to negatively select against random integration. The gene targeting construct was linearized and transfected into the $129 \mathrm{~Sv} / \mathrm{J}$-derived embryonic stem (ES) cell line purchased from Genome Systems. G418-resistant ES cell clones were propagated and screened by subpool selection using PCR primers derived from exon 4 and the neo cassette (Koller and Smithies 1989). PCR-positive pools were further subdivided until individual targeted clones could be verified by Southern blot analysis of NcoI-digested genomic DNA using exon 4 as a probe (see Fig. 1A). Targeted mutagenesis was ob-
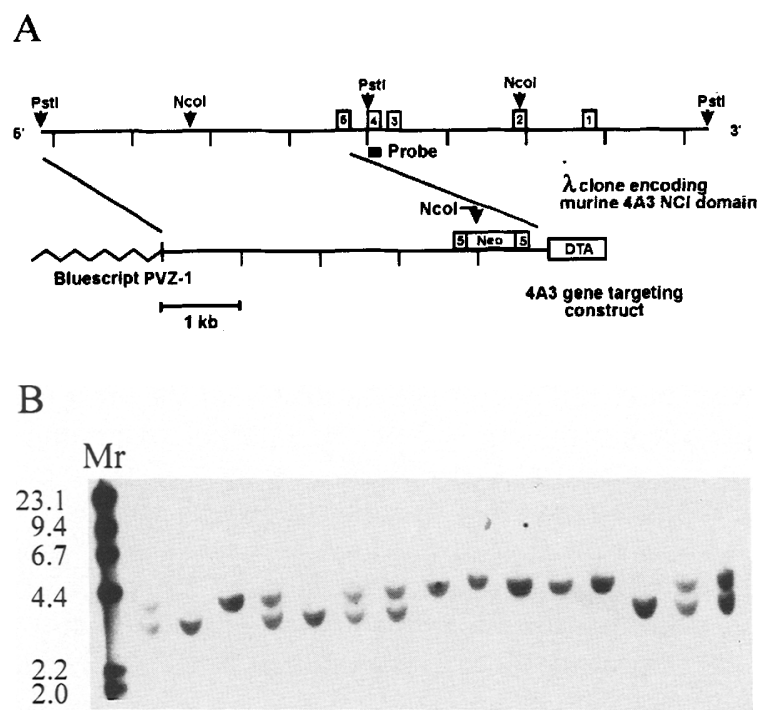

Figure 1. Construction of gene targeting vector and verification of targeted insertion. (A) A 4.2-kb fragment of the indicated genomic portion of the murine COL4A3 gene was modified by inserting the $\mathrm{NeO}$ cassette in exon 5 (in reverse orientation) to disrupt the gene and flanking the construct with the DTA expression cassette to select against random integration. Exons are numbered from the carboxyl terminus of the $\mathrm{NCl}$ domain, because the $5^{\prime}$ end of the mouse gene has not been cloned. $(B)$ DNA from the tails of offspring resulting from a heterozygote cross were digested with $\mathrm{NcOl}$ and analyzed by Southern blot. The transferred DNA was probed using the exon 4 probe indicated in $A$. Molecular weight markers are radiolabeled coliphage $\lambda$ DNA digested with HindIII. Sizes are indicated in kilobase pairs. 
A
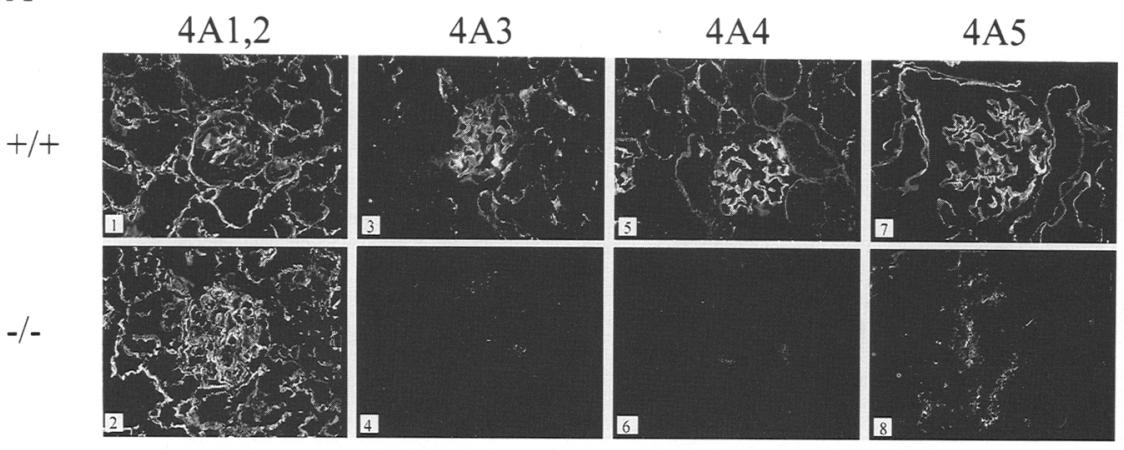

B
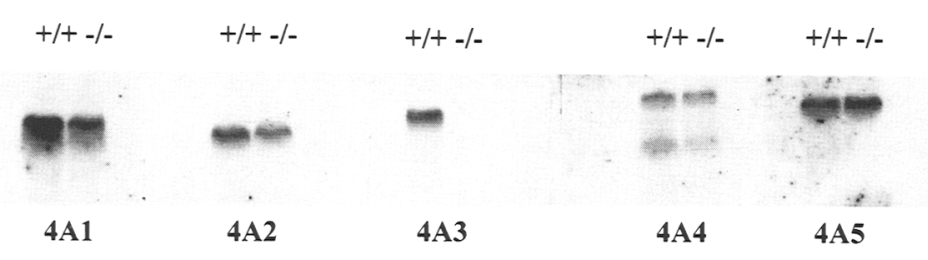

Figure 2. Verification of the COL4A3 knockout. (A) Kidney tissue from control and knockout mice was analyzed by immunofluorescence using antibodies specific for the different type IV collagen chains. The chain specificity of the antibody is indicated on the $x$-axis. Genotypes of the animals are provided on the $y$-axis $1-1-$ denotes homozygosity for the COL4A3 knockout mutation; $+/+$ denotes homozygosity for the normal COL4A3 allele). (B) Northern blot analysis using type IV collagen chain-specific probes. Total RNA $(20 \mu \mathrm{g})$ was fractionated on formaldehyde gels, transferred to nylon, and hybridized with probes specific for the indicated type IV collagen chains. Collagen chain specificity is indicated at bottom. $(+1+)$ Normal mouse; $-1-$ Alport homozygote. served at a frequency of 1 in 50 clones. Targeted clones were injected into 3.5-day embryos and transferred to pseudopregnant foster mothers, and the resulting male chimeras were backcrossed to identify animals capable of transmitting the engineered mutation in the germ line. Germ-line transmission was observed for $100 \%$ of the male chimeras. Germ line-positive $F_{1}$ mice were crossed to derive animals homozygous for the COL4A3 knockout mutation. A typical screen is shown in Figure 1B.

\section{Confirmation of COL4A3 null expression and its} effect on expression of the remaining type IV collagen chains

Expression of the COL4A3, COL4A4, and COL4A5 collagen chains was examined by immunofluorescence using polyclonal antisera specific for the different type IV collagen chains. The results are illustrated in Figure 2A. Whereas these chains localize to GBM and tubular basement membranes in control animals (Fig. 2A3,A5,A7), they are completely absent in animals harboring the COL4A3 knockout mutation (Fig. 2A4,A6,A8). The immunofluorescence patterns for animals heterozygous for the COL4A3 knockout mutation were indistinguishable from the homozygous normal controls (data not shown).

Figure 2, Al (control) and A2 (Alport), illustrates immunofluorescence staining in glomeruli using antibodies against the COL4A1 and COL4A2 chains. Control mice stain primarily in the mesangial matrix, whereas staining in the basement membranes as well as the mesangium is apparent in the diseased mouse. Figure 3, a higher resolution immunoperoxidase stain for the COL4A1 and COL4A2 chains, is provided to more clearly illustrate the differences in classical chain distribution. In the control animal, these type IV collagen chains are expressed in the mesangial matrix and to a much lesser degree in the subendothelial layer of the GBM (Fig. 3A). In the mutant animal, expression of these classical chains is observed throughout the width of the basement membrane, in addition to the mesangial matrix (Fig. 3B). The rounded appearance of the thickened
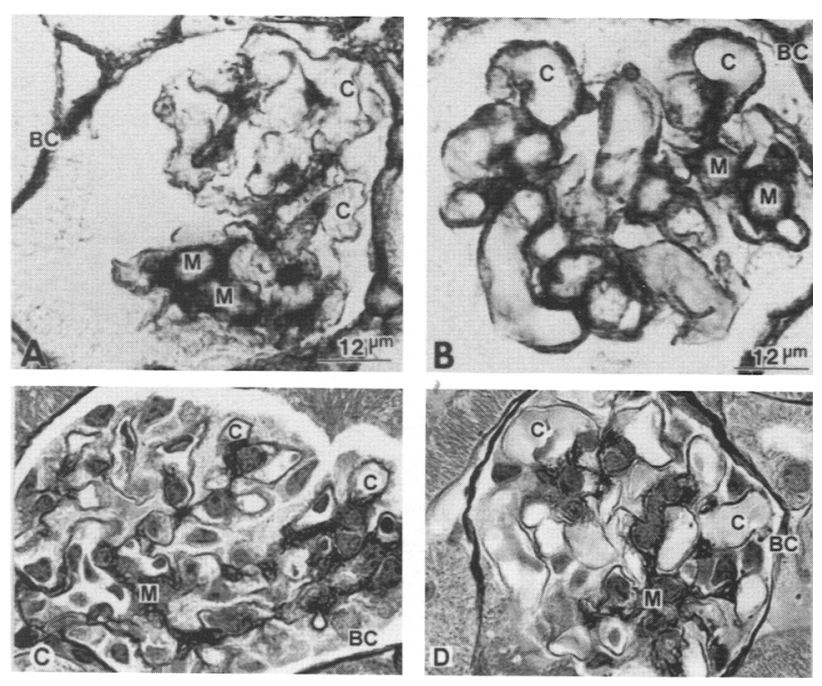

Figure 3. Immunoperoxidase staining for COL4Al and COL4A2 chains in normal and Alport mice. Kidney sections from 8-week-old animals were reacted with antibodies against the classical type IV collagen chains and developed using the immunoperoxidase-based color detection system $(A, B)$ or stained with Jones silver methenamine and counterstained with hematoxylin and eosin $(C, D)$ as described in Materials and Methods. $(A, C)$ Control mouse; $(B, D)$ COL4A3 - - - mouse. (M) Mesangial matrix; (C) glomerular capillary lumen; $(\mathrm{BC})$ Bowman's capsule. 
capillary walls in the Alport glomeruli was a noted characteristic of the COL4A3 knockout mice. Figure 3, C and $\mathrm{D}$, illustrates glomeruli from control and Alport mice, respectively, stained with Jones silver methenamine and counterstained with eosin and hematoxylin. A mild increase in mesangial cells and matrix with focal thickening of the glomerular capillary walls is apparent. All of these observations are consistent with the human phenotype with the exception that, in humans, these collagen chains are not expressed in the tubules (Kashtan and Kim 1992; Gubler et al. 1995; Ninomiya et al. 1995).

To delineate whether the absence of the novel collagen chains (COL4A3, COL4A4, and COL4A5) is a result of events occurring up- or downstream of the mRNA level, Northern blot analysis was performed to examine the mRNAs encoding the five collagen chains. The results in Figure 2B show that, with the exception of collagen COL4A3, the mRNAs for all of the remaining chains are intact and present at the same levels as those observed in control mice. Therefore, the absence of the three collagen chains in the mutant animals is a result of events downstream of transcription and mRNA processing. In addition, these data show that the distribution of the classical collagen chains in the GBM of the mutant (at 7 weeks of age) is not attributable to elevated expression at the level of the mRNA. The small reduction of mRNA for the classical chains in the mutant was not observed in repeated experiments on 7-week-old mice. The lower molecular weight signal observed for COL4A4 is not owing to cross-hybridization with mRNA encoding related type IV collagen chains (see Materials and Methods).

Collectively, these data illustrate that the engineered mutation in the COL4A3 gene has successfully knocked out expression of the COL4A3 protein (and apparently destabilized the message) and that the resulting effect on collagen COL4A4 and COL4A5 expression in the kidney basement membranes is consistent with that observed in the human disease.

\section{Clinical aspects of renal disease progression}

Microhematuria was observed at the earliest time points measured ( 2 weeks of age) and persisted at relatively constant levels (900-3000 corpuscles per $\mathrm{ml}$ of urine) through the course of the disease. Proteinuria was not observed until $\sim 5$ weeks of age and rapidly increased to $10-15 \mathrm{mg} / \mathrm{ml}$ by 6 to 6.5 weeks where it was maintained with little variation until end-stage renal disease. Samples of urine were obtained from mice during a time course aimed at defining onset of proteinuria, fractionated on an $8 \%$ acrylamide gel, and stained with Coomassie blue. The data in Figure 4 illustrate the abrupt nature of the onset of proteinuria and show that a majority of the protein is of a molecular size consistent with murine serum albumin. Blood urea nitrogen levels (measured in a clinical laboratory) began to rise at $\sim 10$ weeks of age and continued to increase through death, which occurred at a mean age of 14 weeks when levels approached 10 times that observed for control animals.

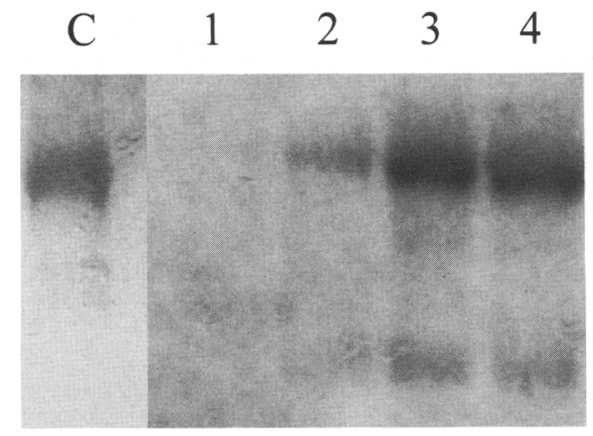

Figure 4. PAGE analysis of onset of proteinuria. Half a microliter of urine from each time point was fractionated on a $10 \%$ SDS-PAGE gel and stained with Coomassie blue. (C) Bovine serum albumin standard (67 kD); (lane 1) 5 weeks; (lane 2) 5.5 weeks; (lane 3) 6 weeks; (lane 4) 6.5 weeks. No staining for control mouse urine was observed, even when $10 \mu$ l was loaded (not shown).

\section{Ultrastructural analysis of the GBM}

Transmission electron microscopy (TEM) was used to examine kidney tissue at 4 weeks (preproteinuria, early disease), 8 weeks (mid-stage), and 14 weeks (end stage) to examine ultrastructural changes that occur with disease progression. The results are presented in Figure 5.

In figure 5, panels $E$ and $F$ provide a high-magnification view of the Alport basement membrane pathology. In control mice (Fig. 5E), the basement membrane has the characteristic trilaminar appearance with the very regular foot processes (pedicles) of the epithelial cells (podocytes) and the obvious finestrations where glomerular filtration across the basement membrane occurs. Panel F illustrates all of the hallmarks of the Alport GBM with focal thinning, multilamination, and splitting of the GBM indicated by arrows. The swelling of the pedicles is also readily apparent.

At 4 weeks, extensive rarification with focal multilamination and thinning is observed in the GBM of the external capillary loops (large arrowhead; Fig. 5B). The internal capillary loops are substantially thinner (small arrowhead; Fig. 5B) than the normal animal (Fig. 5A). There is focal expansion of the mesangial matrix and focal swelling and obliteration of the foot processes (pedicles) of the glomerular epithelial cell (podocyte) involving $<35 \%$ of the surface area. Microvillus formation from the podocytes in areas of basement membrane changes is evident. The pathology is consistent among external cortical glomeruli. By 8 weeks of age (Fig. 5C), the rarification has spread to the internal capillary loops of the GBM. Extensive multilamination of the GBM is observed throughout the glomerulus, with the most extensive thickening observed in the external glomerular capillary loops. An abundance of epithelial cell microvilli are observed, and localized obliteration of the pedicles is common (Fig. 5C, arrowheads). Expansion of the mesangial matrix is apparent in most glomeruli. The phenotypic changes are fairly consistent throughout the external cortical glomeruli. 


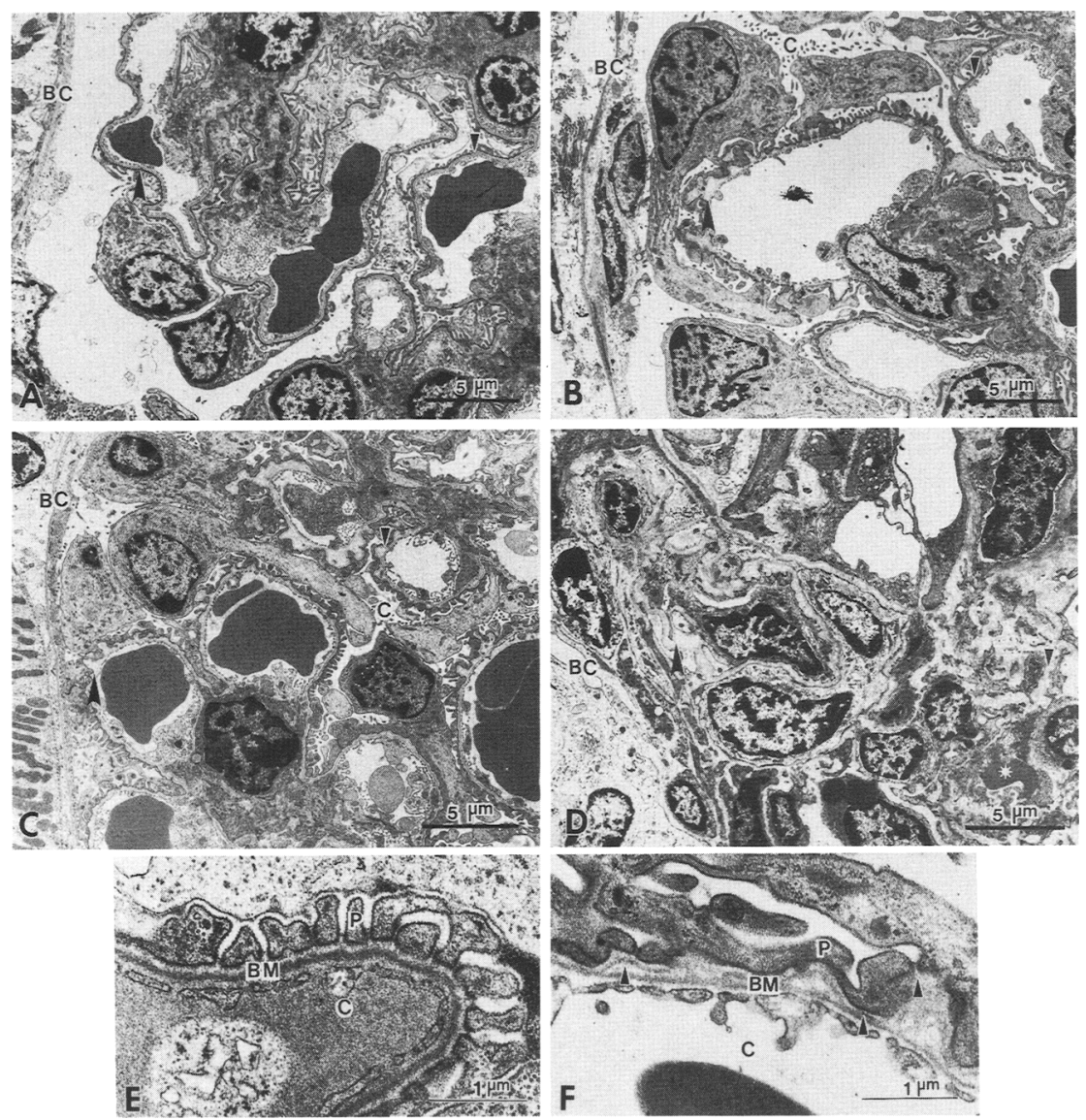

Figure 5. TEM of GBM during Alport disease progression. (A) Normal mouse (8 weeks). Note uniform basal lamina (arrowheads) and characteristic epithelial cell foot processes (pedicles). (B) Affected mouse at 4 weeks. Note the lamination of the lamina densa with focal thickening and irregular contours of the basal lamina (large arrowhead). The foot processes are obliterated in these areas. This change effects primarily the peripheral capillary loops of the glomeruli. A normal (but thin) GBM is denoted (small arrowhead $\mid$ in surrounding an internal capillary loop. Some villous formation by the epithelial cell is noted (C). (C) Affected mouse at 8 weeks. Note extensive lamination of the lamina densa and thickening of the basement membrane swelling and obliteration of the epithelial foot processes. A rarefied internal capillary loop is denoted (small arrowhead) as characteristic of this stage in disease development. $(D)$ Affected mouse at end stage. This fibrotic glomerulus illustrates extensive collapse of glomerular capillary loops [asterisk $\left({ }^{*}\right)$ denotes a corpuscle trapped in a collapsed capillary] and expansion of mesangial matrix. In all four panels, the Bowman's capsule (BC) is denoted to aid in locating external capillary loops. (E) High-magnification illustration of a normal GBM. Note the clearly defined lamina densa flanked by the lamina rara layers of the basement membrane (BM). The pedicles of the gomerular epithelial cells (P) have the characteristic interdigitating appearance. $(F)$ High magnification of the GBM in the diseased animal. Note the characteristic focal multilamination, thinning and splitting (indicated by arrowheads). Pedicles $(\mathrm{P})$ are effaced. For $E$ and $F$, the capillary lumen is indicated $(C)$.

By end stage (end-stage renal disease occurred between 12 and 15 weeks of age) the whole kidney was $30-50 \%$ smaller by mass than that of a sex-matched littermate. The organ appeared pale, with a rough granular surface. About half of the external cortical glomeruli had the appearance of that illustrated in Figure 5D. The capillary walls are mostly collapsed, as evidenced by trapped corpuscles (asterisk; Fig. 5D). The mesangial matrix is grossly expanded and fibrotic. Where basement membranes are still recognizable, they are thick and heavily rarefied. Approximately half of the external cortical glomeruli were not as affected in the end-stage kidney. For these, the appearance was very similar to that illustrated in Figure 5C. All of these observations are consistent with pathology reported for human glomeruli at end stage (Jenis and Lowenthal 1977).

\section{Analysis of the common basement membrane-associated proteins}

The most common proteins found associated with GBM include laminin, fibronectin, entactin (also called nidogen), and HSPG (Dziadek and Timpl 1985; Timpl 1989|. Isoforms of laminin and fibronectin will preferen- tially localize to either the GBM or the mesangial matrix (Thorner et al. 1987; Sanes et al. 1990; Nakapoulou et al. 1993; Virtanen et al. 1995). Entactin is normally found throughout the width of the GBM (Ljubimov et al. 1986), and HSPG localizes to the mesangial matrix with weak expression in the endothelial side of the GBM /Horiguchi et al. 1989). For these studies antibodies for laminin-1 and fibronectin were chosen that recognize epitopes that localize to the mesangial matrix in normal animals. This was done to identify changes in the distribution of the proteins that might occur in parallel with those of basement membrane collagen COL4A1 and COL4A2 chains.

Kidneys were analyzed from normal controls and mice homozygous for the COL4A3 knockout mutation. Animals were chosen at 4 weeks of age ( 2 weeks before the onset of proteinuria) (Fig. 6) at 8 weeks ( 2 weeks after peak proteinuria, thus representing mid-stage in the disease progression), and at 14 weeks of age, which is the mean age of death from end-stage renal failure in the $F_{2}$ mice. The controls panels illustrated in Figure 6 $(\mathrm{A}, \mathrm{E}, \mathrm{I}, \mathrm{M})$ are all derived from the 8-week-old animals; however, no significant differences in staining were observed in the 4-, 8-, or 14-week-old controls in these experiments (data not shown). These time points parallel 
Cosgrove et al.

Figure 6. Immunohistochemical analysis of the basement membrane-associated proteins as a function of Alport disease progression. Kidney sections from either control (C, 8 weeks of age) or Alport mice of varying ages /age denoted in weeks on the $x$-axis) were stained with antibodies specific for the indicated basement-membrane-associated proteins. The specificity of the antibodies is indicated on the $y$-axis. (lam) Laminin; (fib) fibronectin; (hsp) heparan sulfate proteoglycan core protein; (ent) entactin. (Q) The glomerulus of a 14week-old Alport mouse stained with antibodies specific for the collagen COL4Al and COL4A2 chains.

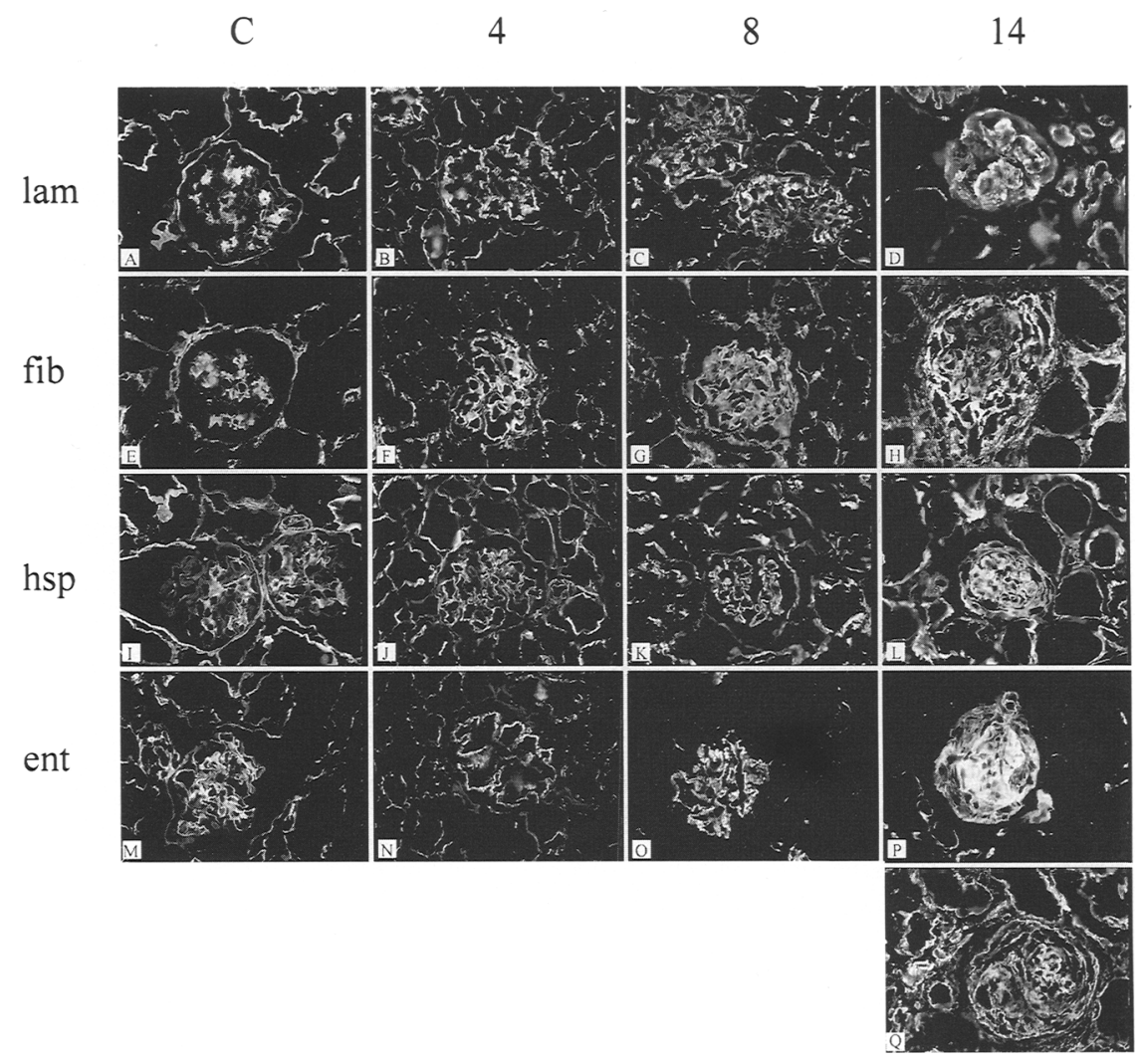

those used in the EM studies (Fig. 5), allowing direct comparison of the two data sets.

Figure 6, A-D, illustrates the changes in laminin-1 expression as a function of disease progression. In control animals, this antisera recognizes epitopes that localize primarily to the mesangial matrix (Fig. 6A). Weaker staining is observed in the endothelial side of the GBM. At 4 weeks of age, a marked difference is observed between the control and the diseased animal (Fig. 6B). Laminin-1 staining localized primarily to the GBM of the outer capillary loops, with weaker staining in the mesangium. This observation parallels the pattern of rarification of the GBM observed by electron microscopy (Fig. $5 B)$. At 8 weeks, laminin-1 staining is most intense in the GBM of the external capillary loops; however, the intense staining is spreading to the interior of the glomerulus, again in close correlation with the pattern for progressive GBM rarification observed by TEM (Fig. 5C). At end stage, laminin-1 staining in the fibrotic glomeruli is most intense in the expanded mesangial matrix, but intense generalized staining for laminin-1 in these collapsed glomeruli is also observed (Fig. 6D).

Staining for fibronectin localized exclusively to the mesangium in the control animals (Fig. 6E). In the affected mice, both mesangial and external capillary staining were observed at 4 weeks of age (Fig. 6F). At 8 weeks intense immunostaining is observed in both the GBM and the mesangium throughout the glomerulus (Fig. 6G). Figure $6 \mathrm{H}$ illustrates intense staining in the collapsed external glomerular capillaries in end-stage glomeruli.
The expanded mesangial matrix is positive for fibronectin; however, the intensity of immunostaining is less than that of the exterior regions in the glomerulus. The walls of the tubules show enhanced staining for fibronectin relative to that observed in the earlier time points, suggesting involvement of tubular basement membranes at this stage of the disease progression. Again, these results parallel the pattern of progressive rarification illustrated in the EM studies (Fig. 5A-D).

Immunofluorescence analysis for HSPG as a function of disease progression is illustrated in Figure $6 \mathrm{I}-\mathrm{L}$. The results for HSPG are much the same as those observed for fibronectin and laminin-1. Again, immunoreactivity that primarily localizes to the mesangial matrix is observed in the GBM of the external capillary loops in the 4-week-old Alport mouse (Fig. 6J). Immunoreactivity spreads to the interior GBM in the 8-week-old animal (Fig. 6K), and the fibrotic end-stage glomeruli stain intensely for HSPG (Fig. 6L).

Entactin is the only basement membrane-associated protein analyzed that localizes exclusively to the GBM of the normal mouse (Fig. 6M). Staining in the 4-weekold Alport mouse indicates involvement of this protein in the rarification of the external capillary GBM at this developmental stage (Fig. 6 N). Virtually $100 \%$ of external cortical glomeruli displayed this floret-like staining. Relative staining of the internal capillary GBM is so weak that they are not visualized. At 8 weeks, again correlating with the TEM data, intense irregular staining in the external capillary loops is observed with the 
spread of the immunoreactivity in the internal capillary GBM (Fig. 6O). It is notable that the relative staining of the tubular basement membranes is similar to that observed in control animals. The enhanced immunoreactivity in the glomerulus in the diseased animal overpowers that observed in the tubules. At end stage, intense generalized glomerular staining is observed throughout the fibrotic glomerulus, with the most intense immunoreactivity observed in the expanded mesangial matrix (Fig. 6P).

Figure $6 \mathrm{Q}$ illustrates the staining pattern in the glomerulus for antisera against the COL4A1 and COL4A2 chains. This panel is provided as a basis for comparison with the staining patterns for the basement membraneassociated proteins to illustrate the coordinated profile for accumulation of these basement membrane constituents in the fibrotic glomerulus. Collectively, the data presented in Figure 6 taken together with the TEM data in Figure 5 create a compelling argument for the involvement of basement membrane-associated proteins in the process of GBM rarification and fibrosis in familial nephritis.

The gross changes in the localization and relative staining intensity of the basement membrane-associated proteins examined in Figure 6 could be caused by elevated transcription of the genes encoding these proteins, activation of expression in nonexpressing cells, or to enhanced stability of the proteins in the diseased GBM. In an attempt to clarify which mechanism is involved, probes for laminin $\beta 2$, laminin $\alpha 1$, laminin $\beta 1$, laminin $\gamma 1$, entactin, and HSPG were cloned from a murine genomic cDNA library, verified by sequencing, and used to probe Northern blots of kidney RNA from control and Alport mice at 7 weeks of age The results are illustrated in Figure 7. All of the probes recognize a single species of mRNA of the approximate molecular size reported for these different messages in the mouse. Visual examination of the data suggests that no substantial changes in

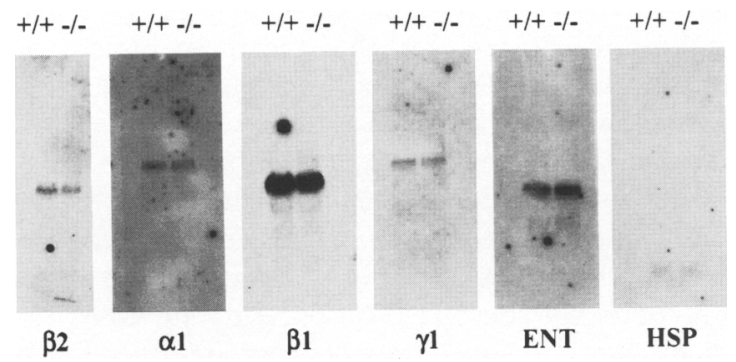

Figure 7. Northern blot analysis for the mRNAs encoding the basement membrane-associated proteins. Total kidney RNA $(20 \mu \mathrm{g})$ from 7 -week-old control $(+1+)$ and Alport $(-1-)$ mice was fractionated on formaldehyde-agarose gels and transferred to nylon supports. Identical blots were hybridized with radiolabeled probes specific for the mRNAs encoding the indicated basement membrane-associated proteins, washed at high stringency, and exposed to X-ray film. ( $\beta 2)$ Laminin $\beta 2$ chain; $(\alpha 1)$ laminin $\alpha 1$ chain; $(\beta 1)$ laminin $\beta 1$ chain $;(\gamma 1)$ laminin $\gamma 1$ chain; (ENT) entactin; (HSPG) heparan sulfate proteoglycan core protein.
mRNA levels for these various basement membrane-associated proteins are evident in the control versus the diseased kidney. PhosphorImage analysis of these blots showed that mRNA levels varied by no more than $25 \%$, which is well within the margin for error for this procedure. Therefore, increases in the apparent amounts of the basement membrane-associated proteins are not reflected by increases in the corresponding mRNAs in the kidney.

Alport syndrome also leads to a moderate high-frequency sensorineural hearing loss and anterior lenticonis in $\sim 50 \%$ of affected people. In outbred $\left(\mathrm{F}_{2}\right)$ mice, auditory brain-stem response measurements give sporadic results. Inbred mice are currently being tested to see whether a reproducible hearing loss is manifest in the mouse model. The anterior portion of the lens does not become cone shaped; however, the interior layer of the basement membrane encasing the anterior lens is irregular in the disease model, rather than the normal smooth appearance in control animals (data not shown). No other notable anomalies were apparent in the Alport mouse model.

\section{Discussion}

The mouse model for the autosomal form of Alport syndrome described in this paper promises to be a useful model for the human disease. Our analysis of this model has provided new information on the molecular mechanism of the disease pathogenesis. It was shown that the absence of the three novel collagen chains is attributable to events downstream of the mRNA level, because the mRNAs encoding COL4A4 and COL4A5 are intact and present at control levels in the mutant mouse. In addition, the model has allowed us to demonstrate that GBM rarification, a hallmark of the disease, occurs first in the GBM of the external capillary loops and progresses, with time, to the interior GBM. The major basement membrane-associated proteins are abnormally distributed in the mutant animal and follow the pattern of rarification. These data are consistent with a model for disease progression in which the accumulation of these associated proteins might play a key role. We divide this discussion into two parts: the first dealing with the implications of these studies on current theories of basement membrane assembly and the second on the molecular nature of disease progression in Alport syndrome.

\section{Basement membrane assembly}

The absence of all three novel chains /COL4A3, COL4A4, and COL4A5) in the GBM is observed for both the X-linked and autosomal forms of Alport syndrome (Kashtan and Kim 1992; Gubler et al. 1995). The reason for this has been the focus of much effort; however, it has not been resolved to any satisfaction. Current theory suggests that the defect could occur at either the level of chain assembly to form monomers or at the level of $\mathrm{NCl}$ dimerization to form one of the critical cross-links in the suprastructure. A combination of these two mechanisms 
may also be at work. At the level of chain association to form trimers, evidence has been presented for the existence of heterotrimers with the composition of two COL4A3 chains with one COL4A4 chain or two COL4A1 chains with one COL4A2 chain (Timpl 1989; Johansson et al. 1991). Homotrimers consisting of COL4A1 chains or COL4A3 chains have also been identified (Saus et al. 1988). To identify interactions at the level of covalent dimerization between individual collagen chains within the heterotrimeric $\mathrm{NCl}$ domains, a procedure involving purification of the heterodimers followed by peptide sequencing was used. The results indicated that these covalent bonds form primarily between like chains (Gunwar et al. 1991). Immunoprecipitation of nondenatured hexamers followed by Western blot analysis confirmed these results; however, it identified a heterodimer of COL4A3 and COL4A5 as a minor component (Kleppel et al. 1992). Collectively, these studies predict that GBM from patients with X-linked Alport syndrome should contain COL4A3 and COL4A4 and that GBM from patients with the autosomal form of the disease should contain COL4A3 and COL4A5 or COL4A4 and COL4A5 /depending on whether the disease is caused by mutations in the COL4A 3 or COL4A4 genes), but this is not the case.

It has been argued that the defective type IV collagen gene in Alport patients might be translated into an aberrant protein that is incorporated into the suprastructure, destabilizing the structure, leading to the loss of all three basement membrane components /Gubler et al. 1995). The Northern blot data provided in this paper illustrates that the mRNA encoding COL4A3 is absent (apparently destabilized) in the COL4A3 knockout, whereas the mRNAs encoding COL4A4 and COL4A5 are intact and present at levels observed in kidney from normal littermates. These data are consistent with a mechanism that involves processes downstream of the mRNA and do not support the suprastructure destabilization theory. However, suprastructure destabilization may, in fact, occur when mutant collagen chains are incorporated into basement membrane, as might be the case for Utah kindred where a single-base substitution converts a conserved cysteine to a serine residue in the mature protein (Zhou et al. 1991).

The one aspect of basement membrane assembly that has been overlooked is the specificity of associations at the level of the $7 \mathrm{~S}$ domain. Clearly, at some level of basement membrane collagen assembly, all three novel collagen chains are required to form GBM. Cell lines derived from the COL4A3 knockout mouse might be used to delineate whether the defect lies in intracellular or extracellular processes of intermolecular association.

\section{Molecular nature of disease progression}

The murine Alport model is particularly useful for experiments aimed at defining the molecular events that accompany the progressive disease pathogenesis. In these studies we described, for the first time in studies of familial nephritis, the temporal and spatial correlation between the progression of the multilaminar rarification of the GBM and the accumulation of basement membrane-associated proteins laminin-1, fibronectin, HSPG, and entactin. The accumulation of these major basement membrane-associated proteins could play a key role in Alport disease pathogenesis; however, whether this is merely a consequence of the primary cause for basement membrane breakdown remains to be determined. It has been proposed, based on amino acid sequence, that normal GBM might contain more cross-links than Alport GBM owing to the high cysteine content of the COL4A3 and COL4A4 chains (Leinonen et al. 1994; Mariyama et al. 1994) providing strength for the molecular sieve function of GBM. If true, all pathogenic effects might be secondary to this primary lesion.

Alternatively, expression of the basement membraneassociated proteins might be owing to induction of their corresponding genes in cells that are in direct contact with the uncharacteristic GBM. It has been demonstrated that basement membranes play critical roles in embryonic development and that components of the extracellular matrix interact with integrin/dystroglycan receptors on cells in contact with the membrane, resulting in changes in gene expression (for review, see Gullberg and Eckblom 1995). Tissue-specific gene expression can be induced by culturing mammary epithelium with basement membrane components (Streuli et al. 1991). Amphibian neural crest cells have been shown to activate different genes when cultured on extracellular matrix from different parts of the embryo (Perris et al. 1988). Altered expression of RNAs for the basement membrane-associated proteins by podocytes and/or endothelial cells in the Alport mouse model could be assessed by in situ hybridization analyses. Such experiments are currently under way.

The basement membrane-associated proteins might be more stable when complexed with basement membrane comprised of the classical chains. The Northern blots in Figure 7 illustrate that the mRNAs encoding the associated proteins are unchanged in Alport mice when compared with normal littermates at 7 weeks of age. It should be noted, however, that Northern blots of total kidney RNA would not necessarily detect changes in specific glomerular cell types.

The distribution of laminin and fibronectin has been examined in the GBM of humans with Alport syndrome (Basta-Jovanovic et al. 1993). Interestingly, these studies report no differences in either the distribution or staining intensity for these two proteins in the GBM for 14 different patients. Similar results were obtained for these two associated proteins using the Samoyed dog model (Thorner et al. 1987), which has recently been shown to harbor a debilitating mutation in the collagen COL4A5 gene, making it a genetically correct model for X-linked Alport syndrome (Zheng et al. 1994). The common feature in these two reports is that antibodies were used that recognize epitopes present in the GBM rather than the mesangial matrix of normal animals. Laminin $\beta 1$ is specific to the mesangial matrix (Sanes et al. 1990). The antisera used in our studies may react primarily with 
laminin $\beta 1$, because it localizes to the mesangial matrix of normal animals

The antisera for fibronectin used in the human and Samoyed dog studies reacted with the GBM of normal subjects. The antisera used in our studies /which was raised against human plasma fibronectin) reacts with epitopes that localize to the mesangial matrix of normal animals. Most of the antisera against fibronectin that have been tested in the kidney react with the mesangial matrix (Funabiki et al. 1990; Nakapoulou et al. 1993). Indeed, the presence of fibronectin has been proposed as a marker for mesangial matrix (Linder et al. 1980).

\section{Materials and methods}

\section{Production of COL4A3 null mice}

An 8.5-kb genomic DNA fragment was cloned from a $129 \mathrm{~Sv} \lambda$ library and sequenced. Direct comparison with the cDNA sequence was used to identify the intron/exon boundaries, and a $4.1-\mathrm{kb}$ Pst fragment containing exon 5 was subcloned into $\mathrm{pB}$ luescript SK $1+$ ) (Stratagene) for use in constructing the targeting vector. The PMC1NeoPA expression cassette was subcloned in reverse orientation into a unique NaeI site in exon 5 , very near the junction between sequence encoding the collagenous and $\mathrm{NCl}$ domains of the protein. The genomic fragment with the antibiotic resistance marker was excised and subcloned into a plasmid containing an expression cassette encoding the DTA for selection against random integration (provided by Ian Maxwell, University of Colorado Health Sciences Center, Denver). The DTA system for negative selection is extremely effective (Palmiter et al. 1987) and has the advantage of not requiring addition of drugs to the media. Studies have found it superior to HSVTK (Yagi et al. 1990). The resulting construct was linearized with SfiI and introduced into the $129 \mathrm{~Sv} / \mathrm{J}$-derived murine ES cell line purchased from Genome Systems via electroporation using a BTX Electrocell Manipulator 600 using the instrument settings suggested by the manufacturer for ES cells. Cells were selected for $\sim 1$ week in $150 \mu \mathrm{g} / \mathrm{ml}$ of geneticin (G418; GIBCO), and the resulting clones were subjected to the PCR subpool selection using the methods described by Koller and Smithies (1989). Positive clones were verified by Southern blot analysis using exon 4 as a probe as outlined in Figure 1A. Targeted clones were injected into 3.5 -day blastocysts and reimplanted into pseudopregnant foster mothers using the methods described by Robertson et al. (1987). The resulting male chimeras were backcrossed with $\mathrm{C} 57 \mathrm{Bl} / 6$ females to assess for transmission in the germ line, which was observed for all of the chimeras tested. The resulting $F_{1}$ mice were crossed to produce the experimental animals used in this study.

\section{Northern blot analysis}

Kidneys were removed and snap-frozen in liquid nitrogen and ground to a powder in liquid nitrogen using a mortar and pestle. The powder was solubilized in TRIzol reagent $(\mathrm{GIBCO})$ using 5 $\mathrm{ml}$ of reagent per kidney. Total cellular RNA was extracted according to the manufacturer's instructions. Twenty micrograms of RNA was fractionated on a $1.0 \%$ agarose/formaldehyde/MOPS gel by electrophoresis at $80 \mathrm{~V}$ for $4 \mathrm{hr}$. Gels were soaked in water for $45 \mathrm{~min}$ and transferred to Hybond-N (uncharged; NEN) by capillary blot overnight using $750 \mathrm{~mm}$ ammonium acetate as a transfer buffer. The RNA was UV crosslinked to the blot using a Stratalinker (Stratagene). Blots were prehybridized in a solution comprised of $50 \%$ formamide, $10 \times$
Denhardt's solution, $1 \mathrm{M} \mathrm{NaCl}, 50 \mathrm{~mm}$ Tris- $\mathrm{HCl}(\mathrm{pH} 7.4), 1 \%$ SDS, and $200 \mu \mathrm{g} / \mathrm{ml}$ of sonicated and denatured salmon sperm DNA. Probes were labeled by random priming to a concentration of $10^{9} \mathrm{cpm} / \mu \mathrm{g}$ and allowed to hybridize overnight at $42^{\circ} \mathrm{C}$. Blots were washed at high stringency and exposed to X-ray film. Relative amounts of specific mRNAs were determined by direct quantification using a Bio-Rad GS-525 PhosphorImager.

\section{Generation of probes}

Probes were isolated from a murine kidney $5^{\prime}$ stretch cDNA library (Clonetech) by PCR amplification using published sequence for the different basement membrane collagen cDNAs and those for the associated proteins. For the basement membrane collagen probes, sequence encoding the conserved $\mathrm{NCl}$ domain was amplified. The primers and conditions used were identical to those used by Miner and Sanes (1994). For collagen COL4Al (Muthukumaran et al. 1989), primers were sense, 5'TCTGTGGACCATGGCTTC- ${ }^{\prime}$; antisense, 5'-TTCTCATGCACACTTGGC-3'. For collagen COL4A2 (Saus et al. 1989), primers were sense, 5'-GGCTACCTCCTGGTGAAG- ${ }^{\prime}$; antisense, 5'-TTCATGCACACTTGGCAG-3'. Both COL4Al and COL4A2 were amplified under the same conditions. $10^{6}$ virions were subjected to 35 cycles of PCR using a hot start and $95^{\circ} \mathrm{C}$ for $30 \mathrm{sec}, 55^{\circ} \mathrm{C}$ for $30 \mathrm{sec}$, and $72^{\circ} \mathrm{C}$ for $1 \mathrm{~min}$. Probes were subcloned and verified by DNA sequence analysis. The inserts were amplified out of the plasmids and purified by agarose gel electrophoresis. Five identical slot blots were produced from dilutions of all five probes, and each blot was hybridized to individual radiolabeled probes to check for cross-hybridization. No detectable cross-hybridization was observed between these probes using the same conditions used for the Northern blot analyses (data not shown).

Probes for the basement membrane-associated proteins were amplified from the same library as the basement membrane collagens. Primers were taken from the 3 ' sequence. For the HSPG core protein (Noonan et al. 1988), primers were sense, 5'-CGGGCCACATTCTCC-3'; antisense, 5'-GGAGTGGCCGTTGCATT-3'. For laminin B2 (Sasaki and Yamada 1987), primers were sense, 5'-ACCAGTACCAAGGCGGA-3'; antisense, 5'-TCATTGAGCTTGTTCAGG-3'. For laminin Bl (Sasaki et al. 1987), primers were sense, 5'-TAGAGGTTATTTTGCAGCAGA-3'; antisense, 5'- TTGGATATCCTCATCAGCTTG-3'. For entactin (Mann et al. 1989), primers were sense, 5'-GTGGTTTACTGGACAGACATC-3'; antisense, 5'CCAATCTGTCCAATAAAGG-3'. For laminin A chain (Deutzmann et al. 1988), primers were sense, 5'-ACACACTCCAAGCCCACAAAAGCAAG- ${ }^{\prime}$; antisense, 5'-GAGGGAAGACTCCTTGTAGGTCAA-3'. For S-laminin (Hunter et al. 1989), primers were sense, 5'-GCAGAGCGGGCACGGAGC$3^{\prime}$; antisense, 5'-TGTACCTGCCATCCTCTCCTG-3'. PCR conditions were identical to those used for the type IV collagen chains.

\section{TEM}

Fresh external renal cortex was minced in $4 \%$ paraformaldehyde, allowed to fix for $2 \mathrm{hr}$, and stored at $5^{\circ} \mathrm{C}$ in PBS. The tissue was washed extensively ( 5 times for $10 \mathrm{~min}$ each at $4^{\circ} \mathrm{C}$ ) with 0.1 M Sorenson's buffer, and postfixed in $1 \%$ buffered osmium tetroxide for $1 \mathrm{hr}$. The tissue was then dehydrated in graded ethanol and finally in propoxylene oxide and embedded in Poly/ Bed 812 following the procedures described by the manufacturer. Glomeruli were identified in $1 \mu \mathrm{M}$ sections stained with toluidine blue, and thin sections were cut at $70 \mathrm{~nm}$ thickness using a Reichert Jung Ultracut E ultramicrotome. Sections were 
mounted onto grids and stained with uranyl acetate and lead citrate. Grid-mounted sections were examined and photographed using a Phillips CM10 electron microscope.

\section{Immunohistology}

Fresh kidney was removed, cut into $3 \mathrm{~mm}$ thick cross sections, embedded in Tissue Tek OCT aqueous compound, and frozen by placing in a $-15^{\circ} \mathrm{C}$ freezer. Sections were cut at $3 \mu \mathrm{M}$ using a Microm (Zeiss) cryostat, and thawed onto poly-L-lysine-coated slides. Slides were fixed for $15 \mathrm{~min}$ by soaking either in cold $95 \%$ ethanol, if they are to be used for staining with the basement membrane collagen-specific antibodies, or with cold acetone for staining with antibodies specific for the basement membrane-associated proteins. Slides were allowed to air dry overnight and were stored desiccated at $-80^{\circ} \mathrm{C}$ until use.

Samples were allowed to reach ambient temperature, then washed three times in cold PBS (pH 7.4). For staining with the antibodies against the type IV collagens, the tissue was pretreated with 0.1 Mmglycine and $6 \mathrm{M}$ urea $(\mathrm{pH} 3.5)$ to denature the protein and expose the antigenic sites. The appropriate dilutions (determined empirically) of the primary antibodies were applied to the sample and allowed to react for $3 \mathrm{hr}$ at $5^{\circ} \mathrm{C}$ in a humidified box. Antibodies were diluted into a solution of $5 \%$ nonfat dry milk in PBS (pH 7.4). The use of nonfat dry milk substantially reduced background fluorescence. Samples were washed four times in ice-cold PBS for 10 min each to remove the primary antibody and then reacted with the appropriate FITCconjugated secondary reagent. All secondary reagents were used at a 1:100 dilution, using $7 \%$ nonfat dry milk in PBS as the diluent. Secondary reagents were allowed to react for $2 \mathrm{hr}$ at $4^{\circ} \mathrm{C}$. The slides were then washed four times with cold PBS followed by the application of antifade mounting media (Vector Laboratories|. Samples were sealed under glass coverslips using clear nail polish.

Immunoperoxidase staining was performed on paraffin-embedded tissue sections cut at $3 \mu \mathrm{M}$. Except for the primary antibody, all specialty reagents were purchased from Vector Laboratories (Burlingame, CA). Dewaxed tissue was digested with $1 \%$ trypsin in $50 \mathrm{~mm}$ Tris- $\mathrm{HCl}$ for $1 \mathrm{hr}$ at $37^{\circ} \mathrm{C}$, washed three times with $\mathrm{PBS}$, reacted with the primary antibody for $30 \mathrm{~min}$ at room temperature, washed three times with PBS, and then reacted with a biotinylated secondary antibody (for antigoat, at 6 $\mu \mathrm{g} / \mathrm{ml}$ of solution) for $30 \mathrm{~min}$ at room temperature. After washing three times with PBS, slides were incubated with streptavidin horseradish peroxidase $(3 \mu \mathrm{g} / \mathrm{ml})$ for $30 \mathrm{~min}$ at room temperature. Following three washed with PBS, antibody binding was developed with the AEC substrate system (Vector AEC SK4200 ) following the procedures described by the manufacturer. Slides were photographed at $1000 \times$ magnification. Jones silver methenamine staining was performed on plastic-embedded specimen as described previously (Cosgrove et al. 1996).

The antibodies against the basement membrane collagen COL4A3 and COL4A4 chains were kindly provided by Joshua Sanes (Washington University School of Medicine, St. Louis, $\mathrm{MO}$. These rabbit antisera were raised against fusion peptides, and their specificity described (Miner and Sanes 1994). Antibody against COL4A5 was a monoclonal antibody (mAb A7), described by Ding et al. (1994) as specific for the COL4A5 chain. Goat antisera against the COL4A1 and COL4A2 chains were purchased from Southern Biotechnology. This antibody has been tested for cross-reactivity by the manufacturer and produces a staining pattern in the glomerulus that is consistent with that observed for other antibody preparations against these chains (Miner and Sanes 1994). Anti-HSPG antibody is a rat monoclonal raised against the HSPG core protein purified from
EHS mouse tumor. The antibody has been tested for cross-reactivity with laminin, collagen type IV, fibronectin, and entactin by Western blot and dot-blot immunoassay by the manufacturer (Chemicon International) and as described elsewhere (Horiguchi et al. 1989). Anti-laminin-1 antibodies are rabbit antisera. The immunogen was purified from EHS basement membrane and purchased from Sigma Immunochemicals. Dot-blot immunoassay, performed by the manufacturer, confirmed the absence of cross-reactivity to collagen IV, fibronectin, vitronectin, and chondroitin sulfate types A, B, and C. Anti-fibronectin is a rabbit antiserum raised against fibronectin purified from human plasma. It has been tested by the manufacturer (Sigma Immunochemicals) against cross-reactivity to collagen IV, laminin, vitronectin, and chondroitin sulfate $A, B$, and $C$ using dotblot immunoassay. Anti-entactin is a rat monoclonal antibody produced using EHS-derived entactin as immunogen. This reagent was purchased from Upstate Biotechnology Incorporated and has been tested for appropriate immunoreactivity as well as for the absence of cross-reactivity with other major basement membrane components by Western blot analysis (Ljubimov et al. 1986).

Immunofluorescence and Jones stained images were recorded and processed using an Olympus $\mathrm{BH} 2$ RFLA fluorescence microscope interfaced with an Applied Imaging Cytovision Ultra image analysis system. Images are captured using a high-resolution black and white video camera. These images can then be modified using the system software. In processing the images, care was taken to approximate closely the fluorescence observed directly on the microscope.

\section{Protein analysis}

Initial measurements of urinary protein were carried out using Albustix (Miles Laboratories) and reading the relative amounts from the color chart provided with the kit. Quantitative measurements were performed using the Bradford assay with prepared reagent from Bio-Rad, according to the manufacturer's instructions. Urine samples were collected from three controls and three littermates homozygous for the COL4A3 knockout mutation at biweekly intervals and $0.5-\mu l$ fractionated by electrophoresis through $10 \%$ denaturing acrylamide gels. The protein was stained with Coomassie blue and photographed. Bovine serum albumin was used as a molecular weight standard.

\section{Acknowledgments}

Our sincerest thanks to Carol Miller for her work in transmission electron microscopy. We thank Joshua Sanes for the kind gift of antibodies, Ian Maxwell for providing the DTA expression cassette, and Alfred Michael for the gift of anti-COL4A5 antibodies. We are grateful to Jeff Pinnt and John (Skip) Kennedy for their help in the preparation of figures and to Kathryn Rodgers for her help in the maintenance and typing of animals. This work was supported by National Institutes of Health (NIH) grants 1 R01 DK50280-01 from the National Institute of Diabetes and Digestive Kidney Diseases and P01 DC01813 from the National Institute for Deafness and other Communication Disorders. R.L.S. was supported by an NIH postdoctoral training fellowship, and J.M.K. was supported by NIH P60 DC00982.

The publication costs of this article were defrayed in part by payment of page charges. This article must therefore be hereby marked "advertisement" in accordance with 18 USC section 1734 solely to indicate this fact.

\section{References}

Antignac, C., B. Knebelmann, L. Drouot, F. Gros, G. Deschenes, 
M.-C. Hors-Clays, J. Zhou, K. Tryggvason, J.-P. Grunfeld, M. Broyer, and M.-C. Gubler. 1994. Deletions in the COL4A5 collagen gene in X-linked Alport syndrome. Am. Soc. Clin. Invest. 93: 1195-1207.

Atkin, C.L., M.C. Gregory, and W.A. Border. 1988. Alport syndrome. In Diseases of the kidney (ed. R.W. Schrier and C.W. Gottschalk), pp. 617-641. Little, Brown, Boston, MA.

Barker, D.E., S.L. Hostikka, J. Zhou, L.T. Show, A.R. Oliphant, S.C. Gerken, M.C. Gregory, M.H. Skolnick, C.L. Atkin, and $\mathrm{K}$. Tryggvason. 1990. Identification of mutations in the COL4A5 collagen gene in Alport syndrome. Science 248: 1224-1227.

Basta-Jovanovic, G., M. Savin, A.Z. Jovanovic, R. Veljovic, and M. Sindjic. 1993. Laminin, fibronectin, and goodpasture antigen detection in patients with alport's syndrome. Renal Failure 15: 503-508.

Cosgrove, D., G. Samuelson, and J. Pinnt. 1996. Expression of basement membrane type IV collagen chains during postnatal development in the murine cochlea. Hearing Res. (in press).

Davaris, P. 1993. The glomerular distribution of laminin and fibronectin in glomerulonephritis. Histol. Histopath. 8: $521-526$.

Derry, C.J., M. Pickering, C. Baker, and C.D. Pusey. 1994. Identification of the Goodpasture antigen COL4A3 NCl, and four other $\mathrm{NCl}$ domains of type IV collagen, by amino terminus sequence analysis of human glomerular basement membrane separated by two-dimentional electrophoresis. Exp. Nephrol. 2: 249-256.

Desjardins, M., F. Gros, J. Weislander, M.-C. Gubler, and M. Bendayan. 1990. Heterogeneous distribution of monomeric elements from the globular (NC1) domain of type IV collagen in renal basement membranes as revealed by high resolution quantitative immunohistochemistry. Lab. Invest. 63: 637646.

Deutzmann, R., J. Huber, K.A. Schmetz, I. Oberbäumer, and L. Hartl. 1988. Structural study of long arm fragments of laminin. Eur. J. Biochem. 177: 35-45.

Ding, J., C.E. Kashtan, W.W. Fan, M.M. Kleppel, M.J. Sun, R. Kalluri, E.G. Neilson, and A.F. Michael. 1994. A monoclonal antibody marker for alport syndrome identified the alport antigen as the $\alpha 5$ chain of type IV collagen. Kidney Int. 46: 1504-1506.

Dziadek, M. and R. Timpl. 1985. Expression of nidogen and laminin in basement membranes during mouse embryogenesis and in teratocarcinoma cells. Dev. Biol. 111: 372-382.

Funabiki, K., S. Horikoshi, Y. Tomino, Y. Nagai, and H. Koide. 1990. Immunohistochemical analysis of extracellular components in the glomerular sclerosis of patients with glomerulonephritis. Clin. Nephrol. 34: 239-246.

Gubler, M.-C., B. Knebelmann, A. Beziau, M. Broyer, Y. Pirson, F. Haddoum, M.M. Kleppel, and C. Antignac. 1995. Autosomal recessive Alport syndrome: Immunohistochemical study of type IV collagen chain distribution. Kidney Int. 47: 1142-1147.

Gullberg, D. and P. Eckblom. 1995 Extracellular matrix and its receptors during development. Int. J. Dev. Biol. 39: 845-854.

Gunwar, S., F. Ballester, R. Kalluri, J. Timoneda, A.M. Chonko, S.J. Edwards, M.E. Noelken, and B.G. Hudson. 1991. Glomerular basement membrane. J. Biol. Chem. 266: 1531815324.

Horiguchi, Y., J.R. Couchman, V. Ljubimov, H. Yamasaki, and J.-D. Fine. 1989. Distribution, ultrastructural localization, and ontogeny of the core protein of a heparan sulfate proteoglycan in human skin and other basement membranes. $J$. Histochem. Cytochem. 37: 961-970.
Hudson, B.G., S. Reeders, and K. Tryggvason. 1993. Type IV collagen: Structure, gene organization, and role in human diseases. J. Biol. Chem. 268: 26033-26036.

Hunter, D.D., S. Vandana, J.P. Merlie, and J.R. Sanes. 1989. A laminin-like adhesive protein concentrated in the synaptic cleft of the neuromuscular junction. Nature 338: 229-234.

Jenis, E.H. and D.T. Lowenthal. 1977. Hereditary nephritis (Alport's syndrome). In Kidney biopsy interpretation (ed. E.H. Jenis and D.T. Lowenthal), pp. 125-136. F.A. Davis Company, Philadelphia, PA.

Johansson, C., R. Butkowski, and J. Wieslander. 1991. Characterization of monoclonal antibodies to the globular domain of collagen IV. Conn. Tissue Res. 25: 229-241.

Johnsson, L.-G. and I.K. Arenberg. 1981. Cochlear abnormalities in Alport's syndrome. Arch. Otolarynogol. 107: 340-349.

Kashtan, C.E. and Y. Kim. 1992. Distribution of the $\alpha 1$ and $\alpha 2$ chains of collagen IV and of collagens V and VI in Alport syndrome. Kidney Int. 42: 115-126.

Kleppel, M.M., P.A. Santi, J.D. Cameron, J. Wieslander, and A.F. Michael. 1989. Human tissue distribution of novel basement membrane collagen. Am. J. Pathol. 134: 813-825.

Kleppel, M.M., W.W. Fan, H.I. Cheong, and A.F. Michael. 1992. Evidence for separate networks of classical and novel basement membrane collagen. J. Biol. Chem. 267: 4137-4142.

Koller, B.H. and O. Smithies. 1989. Inactivating the $\beta 2$-microglobulin locus in mouse embryonic stem cells by homologous recombination. Proc. Natl. Acad. Sci. 86: 8932-8935.

Leinonen, A., M. Mariyama, T. Mochizuki, K. Tryggvason, and S. Reeders. 1994. Complete primary structure of the human type IV collagen $\alpha 4$ (IV) chain. Comparison with structure and expression of the other $\alpha($ IV $)$ chains. I. Biol. Chem. 269: 26172-26177.

Lemmink, H.H., T. Mochizuki, L.P.W.J. van den Heuvel, C.H. Schroder, A. Barrientos, L.A.H. Monnens, B.A. van Oost, H.G. Brunner, S.T. Reeders, and H.J.M. Smeets. 1994. Mutations in the type IV collagen $\alpha 3$ (COL4A3) gene in autosomal recessive Alport syndrome. Hum. Mol. Genet. 3: 12691273.

Linder, E., A. Miettinen, and J. Törnroth. 1980. Fibronectin as a marker for the glomerular mesangium in immunohistology of kidney biopsies. Lab. Invest. 42: 70-75.

Ljubimov, A.V., A.V. Afanasjeva, L.V. Litvinova, and V.M. Senin. 1986. Basement membrane components produced by a mouse ascites teratocarcinoma TB 24: Analysis with monoclonal and polyclonal antibodies. Exp. Cell Res. 165: 530540.

Maki, S. 1989. Glomerular localization of type III collagen in human kidney disease. Kidney Int. 35: 1203-1211.

Mann, K., R. Deutzmann, M. Admailley, R. Timpl, L. Raimondi, Y. Yamada, T. Pan, D. Conway, and M.-L. Chu. 1989. Amino acid sequence of mouse nidogen, a multidomain basement membrane protein with binding activity for laminin, collagen IV cells. EMBO $I$. 8: 65-72.

Mariyama, M., A. Leinonen, T. Mochizuki, K. Tryggvason, and S.T. Reeders. 1994. Complete primary structure of the human $\alpha 3$ (IV) collagen chain. Coexpression of the $\alpha 3$ (IV) and $\alpha 4$ (IV) collagen chains in human tissues. I. Biol. Chem. 269: 23013-23017.

Miner, J.H. and J.R. Sanes. 1994. Collagen IV $\alpha 3, \alpha 4$, and $\alpha 5$ chains in rodent basal lamina: Sequence, distribution, association with laminins, and developmental switches. I. Cell Biol. 127: 879-891.

Mochizuki, T., H.H. Lemmink, M. Mariyama, C. Antignac, M.C. Gubler, Y. Pirson, C. Verellen-Dumoulin, B. Chan, C.H. Schroder, H.J. Smeets, and S.T. Reeders. 1994. Identification of mutations in the $\alpha 3$ (IV) and $\alpha 4$ (IV) collagen genes in au- 
tosomal recessive Alport syndrome. Nature Genet. 8: 77-82. Muthukumaran, G., B. Blumberg, and M. Kurkinen. 1989. The complete primary structure for the alpha-1 chain of mouse collagen IV. Differential evolution of collagen IV domains. $J$. Biol. Chem. 264: 6310-6317.

Myers, G.J. and H.R. Tyler. 1972. The etiology of deafness in Alport's syndrome. Arch. Otolaryng. 96: 333-340.

Nakapoulou, L., K. Stefanaki, P.M. Zeis, J. Papadakis, J. Boletis, G. Vosnidis, and P. Davaris. 1993. The glomerular distribution of laminin and fibronectin in glomerulonephritis. Histol. Histopath. 8: 521-526.

Ninomiya, Y., M. Kagawa, K.-I. Iyama, I. Naito, Y. Kishiro, J.M. Seyer, T. Sugimoto, and Y. Sado. 1995. Differential expression of two basement membrane collagen genes, COL4A6 and COL4A5, demonstrated by immunofluorescence staining using peptide-specific monoclonal antibodies. I. Cell Biol. 130: 1219-1229.

Noonan, D.M., E.A. Horigan, S.R. Ledbetter, G. Vogeli, M. Sasaki, Y. Yamada, and J.R. Hassell. 1988. Identification of cDNA clones encoding different domains of the basement membrane heparan sulfate proteoglycan. I. Biol. Chem. 263: 16379-16387.

Palmiter, R.D., R.R. Behringer, C.J. Quaife, I.H. Maxwell, and R.L. Brinster. 1987. Cell lineage ablation in transgenic mice by cell specific expression of a toxin gene. Cell 50: 435-443.

Perris, R., Y. von Boxberg, and J. Lofberg. 1988. Local embryonic matrices determine region-specific phenotypes in neural crest cells. Science 241: 86-89.

Robertson, E.J. 1987. In Teratocarcinomas and embryonic stem cells, a practical approach, pp. 113-151. IRL Press Limited, Oxford, UK.

Sanes, J.R., E. Engvall, R. Butkowski, and D.D. Hunter. 1990. Molecular heterogeneity of basal laminae: Isoforms of laminin and collagen IV at the neuromuscular junction and elsewhere. I. Cell Biol. 111: 1685-1699.

Sasaki, M. and Y. Yamada. 1987. The laminin B2 chain has a multidomain structure homologous to the Bl chain. J. Biol. Chem. 262: 17111-17117.

Sasaki, M., S. Kato, K. Kohno, G.R. Martin, and Y. Yamada. 1987. Sequence of the cDNA encoding the laminin Bl chain reveals a multidomain protein containing cysteine-rich repeats. Proc. Natl. Acad. Sci. 84: 935-939.

Saus, J., J. Wieslander, J.P.M. Langeveld, S. Quinoes, and B.G. Hudson. 1988. Identification of the Goodpasture antigen as the $\alpha 3$ (IV) chain of collagen IV. I. Biol. Chem. 263: 13374 13380.

Saus, I., S. Quinones, A. MacKrell, B. Blumberg, G. Muthukumaran, T. Pihlajaniemi, and M. Kurkinen. 1989. The complete primary structure of mouse $\alpha 2$ (IV) collagen. I. Biol. Chem. 264: 6318-6324.

Streuli, C.H., N. Bailey, and M.J. Bissel. 1991. Control of mammary epithelial differentiation: Basement membrane induces tissue-specific gene expression in the absence of cellcell interaction and morphological polarity. J. Cell. Biol. 115: 1383-1395.

Sugimoto, M., T. Oohashi, and Y. Ninomiya. 1994. The genes COL4A5 and COL4A6, coding for basement membrane collagen chains $(\alpha 5$ (IV) and $\alpha 6$ (IV), are located head-to-head in close proximity on human chromosome Xq22 and COL4A6 is transcribed from two alternative promoters. Proc. Natl. Acad. Sci. 91: 11679-11683.

Thomas, T. and M. Dziadek. 1993. Genes coding for basement membrane glycoproteins laminin, nidogen, and collagen IV are differentially expressed in the nervous system and by epithelial, endothelial, and mesenchymal cells of the mouse embryo. Exp. Cell Res. 208: 54-67.
Thompson, S.M., J.P. Deady, H.E. Willshaw, and R.H.R. White. 1987. Ocular signs in Alport's syndrome. Eye 1: 146-153.

Thorner, P., B. Jansen, R. Baumal, V.E. Valli, and A. Goldberger. 1987. Samoyed hereditary glomerulopathy: Immunohistochemical staining of basement membranes of kidney for laminin, collagen type IV, fibronectin, and Goodpasture antigen, and correlation with electron microscopy of glomerular capillary basement membranes. Lab. Invest. 56: 435.

Timpl, R. 1989. Structure and biological activity of basement membrane proteins. Eur. J. Biochem. 180: 487-5042.

Timpl, R., H. Wiedemann, V. van Delden, H. Furthmayr, and K. Kuhn. 1981. A network model for the organizaiton of type IV collagen molecules in basement membranes. Eur. I. Biochem. 120: 203-211.

Virtanen, I., L. Laitinen, and M. Korhonen. 1995. Differential expression of laminin polypeptides in developing and adult human kidney. I. Histochem. and Cytochem. 43: 621-628.

Wester, D.C., C.L. Atkin, and M.C. Gregory. 1995. Alport syndrome: Clinical update. I. Am. Acad. Audiol. 6: 73-79.

Yagi, T., Y. Ikawa, Y. Shigetani, N. Takeda, I. Mabuchi, T. Yamamoto, and S. Aizawa. 1990. Homologous recombination at c-fyn locus of mouse embryonic stem cells with use of diptheria toxin A-fragment gene in negative selection. Proc. Natl. Acad. Sci. 87: 9918-9922.

Yoshioka, K., T. Takemura, M. Tohda, N. Akano, H. Miyamoto, A. Ooshima, and S. Maski. 1989. Glomerular localization of type III collagen in human kidney disease. Kidney Int. 35: 1203-1211.

Zheng, K., P.S. Thorner, P. Marrano, R. Baumal, and R.R. McInnis. 1994. Canine X chromosome-linked hereditary nephritis: A genetic model for human $\mathrm{X}$-linked hereditary nephritis resulting from a single base mutation in the gene encoding $\alpha 5$ chain of collagen type IV. Proc. Natl. Acad. Sci. 91: 39893993.

Zhou, J., D.F. Barker, S.L. Hostikka, M.C. Gregory, C.L. Atkin, and K. Tryggvason. 1991. A single base mutation in the $\alpha 5$ (IV) collagen chain converting a conserved cysteine to serine in Alport syndrome. Genomics 9: 10-18.

Zhou, J., T. Mochizuki, H. Smeets, C. Antignac, P. Laurila, A. de Paepe, and K. Tryggvason. 1993. Deletion of the paired $\alpha 5$ (IV) and $\alpha 6$ (IV) collagen genes in inherited smooth muscle tumors. Science 261: 1167-1169.

Zhou, K. Tryggvason, J.P. Grunfeld, M. Broyer, and M.C. Gubler. 1994. Deletions in the COL4A5 collagen gene in $\mathrm{X}$-linked Alport syndrome. Characterization of the pathological transcripts in nonrenal cells and correlation with disease expression. J. Clin. Invest. 93: 1195-1207. 


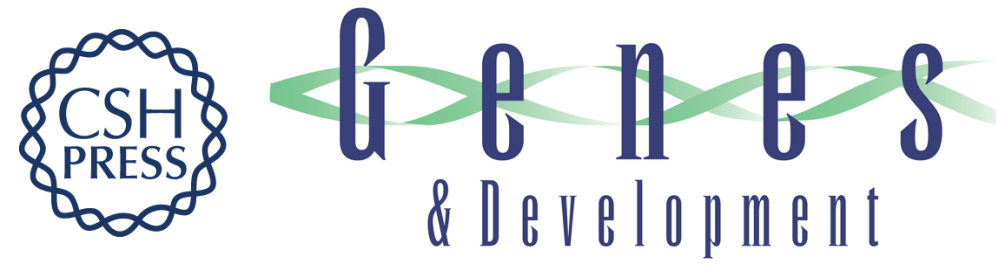

\section{Collagen COL4A3 knockout: a mouse model for autosomal Alport syndrome.}

D Cosgrove, D T Meehan, J A Grunkemeyer, et al.

Genes Dev. 1996, 10:

Access the most recent version at doi:10.1101/gad.10.23.2981

References This article cites 58 articles, 22 of which can be accessed free at:

http://genesdev.cshlp.org/content/10/23/2981.full.html\#ref-list-1

License

Email Alerting

Service

Receive free email alerts when new articles cite this article - sign up in the box at the top right corner of the article or click here.

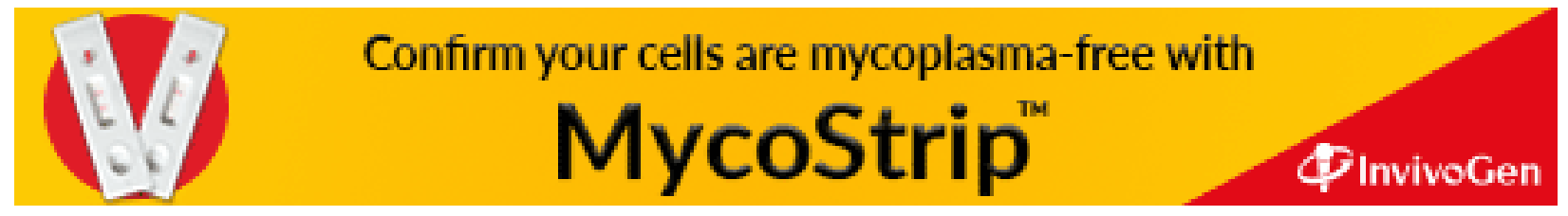

